Research paper

\title{
4-Component correlated all-electron study on Eka-actinium Fluoride (E121F) including Gaunt interaction: Accurate analytical form, bonding and influence on rovibrational spectra
}

\author{
Davi H.T. Amador ${ }^{\text {a }}$, Heibbe C.B. de Oliveira ${ }^{\text {b }}$, Julio R. Sambrano ${ }^{c}$, Ricardo Gargano ${ }^{\text {, }}$, \\ Luiz Guilherme M. de Macedo ${ }^{\mathrm{a}, \mathrm{d}, *}$ \\ ${ }^{a}$ Faculdade de Biotecnologia, Instituto de Ciências Biológicas, Universidade Federal Do Pará (UFPA), Belém, PA 66075-110, Brazil \\ ${ }^{\mathrm{b}}$ Laboratório de Estrutura Eletrônica E Dinâmica Molecular (LEEDMOL), Instituto de Química, Universidade de Brasília (UnB), P.0. Box 04478, Brasília, DF 70910-900, Brazil

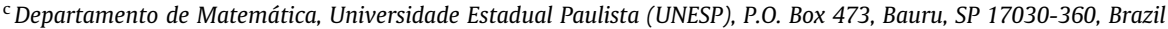 \\ ${ }^{\mathrm{d}}$ Instituto de Física, Universidade de Brasília (UnB), P.O. Box 04455, Brasília, DF 70919-970, Brazil
}

\section{A R T I C L E I N F O}

\section{Article history:}

Received 4 August 2016

In final form 10 September 2016

Available online 12 September 2016

\begin{abstract}
A B S T R A C T
A prolapse-free basis set for Eka-Actinium $(\mathrm{E} 121, \mathrm{Z}=121)$, numerical atomic calculations on $\mathrm{E} 121$, spectroscopic constants and accurate analytical form for the potential energy curve of diatomic E121F obtained at 4-component all-electron $\operatorname{CCSD}(\mathrm{T})$ level including Gaunt interaction are presented. The results show a strong and polarized bond $(\approx 181 \mathrm{kcal} / \mathrm{mol}$ in strength) between $\mathrm{E} 121$ and $\mathrm{F}$, the outermost frontier molecular orbitals from E121F should be fairly similar to the ones from AcF and there is no evidence of break of periodic trends. Moreover, the Gaunt interaction, although small, is expected to influence considerably the overall rovibrational spectra.
\end{abstract}

(c) 2016 Elsevier B.V. All rights reserved.

\section{Introduction}

The Periodic Table has 15 superheavy elements (SHE) known [1] and it is now completed up to its seventh period with the discovery of elements $\operatorname{Og}[2](Z=118)$ and Ts $[3](Z=117)$. The SHE are artificially produced elements with $Z>103$, that usually have short half-lives and low production rates that makes their experimental studies limited to just a few isotopes that can be investigated by atom-at-time techniques [4].

As a consequence, theoretical studies on SHE are of relevance since in most cases they are the only way to obtain reliable chemical, physical or spectroscopic properties on molecules containing SHE. This importance is especially true for SHE from eka-francium $(Z=119)$ onwards, where no element has been synthetized or discovered so far: attempts to produce eka-francium and ekaradium, as well the confirmation of the existence [5] in nature of a long lived isotope of element eka-thorium $(Z=122)$ have failed.

Little is known about the chemistry and spectroscopic properties of SHE form the $8^{\text {th }}$ period. There are relatively few theoretical

\footnotetext{
* Corresponding author at: Faculdade de Biotecnologia, Instituto de Ciências Biológicas, Universidade Federal Do Pará (UFPA), Belém, PA 66075-110, Brazil.

E-mail address: lgm@ufpa.br (L.G.M. de Macedo).
}

studies in the literature about molecules with these elements [6-9] perhaps due to the high level methods involved in the description of their electronic structure. Besides a good treatment of electron correlation effects, not only the inclusion of scalar relativistic and spin orbit coupling are mandatory, but also Gaunt, Breit or even higher level Quantum Electrodynamics effects (QED) may also be important $[10,11]$.

Regarding the element E121, there are only atomic studies to the best of our knowledge: it seems based on these studies [1214] that the ground state of the E121 (eka-actinium) should be [Uuo] $8 \mathrm{~s}^{2} 8 \mathrm{p}_{1 / 2}^{1}$ in contrast with the $7 \mathrm{~s}^{2} 6 \mathrm{~d}_{3 / 2}^{1}$ of Actinium. In addition, Eliav [12] et al. found that the Breit term on most transitions are rather small $(0.01-0.02 \mathrm{eV})$ but goes up to $0.1 \mathrm{eV}$ for transitions involving f electrons.

In this contribution we present a basis set suitable for 4component molecular calculations, relativistic numerical calculations for E121 atom, as well as molecular relativistic calculations at 4-Component $\operatorname{CCSD}(\mathrm{T})$ and B3LYP levels with (and without) inclusion of Gaunt interaction. Besides the generation of the basis set for E121, the aim is twofold: to obtain an accurate analytical form for the potential energy curve for E121F and to investigate the influence of Gaunt interaction on spectroscopic constants, rotational spectra and bonding. Further discussion on bonding is also presented, showing similarities with E121F and AcF. 


\section{Method and computational details}

All atomic basis set expansion calculations for generating the gaussian basis set for E121 were performed using the DFRATOM program [15] with a protocol employed previously [16] on development of basis sets for SHE, so it will be briefly described:

(a) The polynomial version of the Generator Coordinate DiracFock (pGCDF) method was adopted [17];

(b) The pGCDF parameters were optimized by employing the Downhill Simplex Algorithm;

(c) The value of the speed of light used was c $=137.0359895$ in atomic units;

(d) The ground state configuration adopted for E121 was [Og] $8 \mathrm{~s}^{2} 8 \mathrm{p}^{1}$

(e) The atomic mass for the E121́s theoretically most stable isotope was 320 a.m.u., as suggested by Chowdhury, Samanta and Basu [18].

In order to assess the quality of the basis set, numerical calculations for E121 were performed using a modified version of GRASP [19] program, where the Gaussian nuclear model was introduced as suggested by Visscher and Dyall [20].

All Molecular calculations were performed using the DIRAC12 program Package [21]. For the relativistic 4-component $\operatorname{CCSD}(\mathrm{T})$ method [22,23], the active space was selected by 26 electrons corresponding to valence $6 d^{10} 7 s^{2} 7 p^{6} 8 s^{2} 8 p^{1}$ from E121 and the $2 p^{5}$ electrons from fluorine, and it was restricted to the 280 lowest virtual spinors due to limitations of computational resources. In turn, the Gaunt interaction term in Dirac program is limited to DiracHartree-Fock (DHF) and DFT calculations [24], so it could only be treated additively to obtain correlated results. In all calculations the (SS|SS) two electron integrals were neglected and replaced by a charge [25].

The polarization $\mathrm{g}$ functions were chosen from the relativistic universal basis set grid [26] as follows: first, a potential energy curve (PEC) was obtained for E121F in order to get a preliminary minimum distance $\mathrm{R}_{\mathrm{e}}$. At this preliminary $\mathrm{R}_{\mathrm{e}}, 5$ " $\mathrm{g}$ " functions were selected in order to obtain the lowest total energy at $\operatorname{CCSD}(\mathrm{T})$ level. Then, the final PEC was generated at 100 different distances from 3.0 up to 140 bohr. Additional 4-component single point calculations were performed on AcF (Actinium Fluoride) using Dyall's triple-zeta basis set [27] at equilibrium distance [28] of $4.027 \mathrm{bohr}$ in order to obtain the dipole moment $\mu_{e}$ and information about valence orbitals. [29],

The obtained final PEC was fitted using the q-Rydberg function

$V^{q R y d}([c], \rho)=-D_{e}^{q R y d}\left(1+\sum_{j=1}^{m^{\prime}} c_{j} \rho^{j}\right) \exp _{d}\left(c_{1} \rho\right)$

where $D_{e}^{q R y d}$ is the dissociation energy, the d-exponential defined as $\exp _{d}\left(c_{1} \rho\right) \equiv\left[1+c_{1} d \rho\right]^{\frac{1}{d}}, \rho=R-R_{e}$, and $R_{e}$ is the distance of equilibrium in the diatomic system. The minimization procedure for the PEC fitting was performed within a hybrid methodology based on the Simplex and Generalized Simulation Annealing [30] methods. The choice of the degree of the curve fit was made to obtain the best accuracy in the analytical form. In addition, in order to confirm the good quality of the analytical form, the rovibrational constants were obtained by two different approaches.

The first is the Discrete Variable Representation [31] (DVR) in which the electronic energies enter the matrix Schrödinger nuclear equation as potentials. The solution of the Schrödinger nuclear equation gives the rovibrational energies $E(v, J)$, where $v$ and $J$ are the vibrational and rotational quantum numbers. Since the $E(v, J)$ obey the relation

$$
\begin{aligned}
E(v, J)= & \omega_{e}\left(v+\frac{1}{2}\right)-\omega_{e} x_{e}\left(v+\frac{1}{2}\right)^{2}+\omega_{e} y_{e}\left(v+\frac{1}{2}\right)^{3}+\cdots \\
& +\left[B_{e}-\alpha_{e}\left(v+\frac{1}{2}\right)+\gamma_{e}\left(v+\frac{1}{2}\right)^{2}+\cdots\right] J(J+1)+\ldots
\end{aligned}
$$

where $B_{e}=h / 8 \pi^{2} C I_{e}$ is the rotational constant, $I_{e}$ is the moment of inertia and $c$ is the velocity of light, one can substitute $E(v, J)$ into the following [32] system of equations to obtain the rovibrational spectroscopic constants:

$$
\begin{aligned}
& \omega_{e}=\frac{1}{24}\left[14\left(E_{1,0}-E_{0,0}\right)-93\left(E_{2,0}-E_{0,0}\right)+23\left(E_{3,0}-E_{1,0}\right)\right] \\
& \omega_{e} x_{e}=\frac{1}{4}\left[13\left(E_{1,0}-E_{0,0}\right)-11\left(E_{2,0}-E_{0,0}\right)+3\left(E_{3,0}-E_{1,0}\right)\right] \\
& \omega_{e} y_{e}=\frac{1}{6}\left[3\left(E_{1,0}-E_{0,0}\right)-3\left(E_{2,0}-E_{0,0}\right)+3\left(E_{3,0}-E_{1,0}\right)\right] \\
& \alpha_{e}=\frac{1}{8}\left[-12\left(E_{1,1}-E_{0,1}\right)+4\left(E_{2,1}-E_{0,1}\right)+4 \omega_{e}-23 \omega_{e} y_{e}\right] \\
& \gamma_{e}=\frac{1}{4}\left[-2\left(E_{1,1}-E_{0,1}\right)+\left(E_{2,1}-E_{0,1}\right)+2 \omega_{e} x_{e}-9 \omega_{e} y_{e}\right]
\end{aligned}
$$

The second method is the Dunham's method [33], and it is worth to comment how it was implemented in our code. Since the potential of a diatomic molecule can be expanded in terms of Taylor series as derivatives of $\mathrm{V}(\mathrm{R})$ with respect to $\mathrm{R}$ and centered at $R_{e}$,

$V(R)=V\left(R_{e}\right)+\frac{1}{2 !}\left(\frac{d^{2} V}{d R^{2}}\right)_{\operatorname{Re}}\left(R-R_{e}\right)^{2}+\frac{1}{3 !}\left(\frac{d^{3} V}{d R^{3}}\right)_{\mathrm{Re}}\left(R-R_{e}\right)^{3}+\cdots$

this expansion can be rewritten in a more convenient notation, making $\rho=R-R_{e}$ and $f_{n}=\left(\frac{d^{n} V}{d R^{n}}\right)$, as

$V=V(0)+\frac{1}{2} f_{2} \rho^{2}+\frac{1}{6} f_{3} \rho^{3}+\frac{1}{24} f_{4} \rho^{4}+\frac{1}{120} f_{5} \rho^{5}+\frac{1}{720} f_{6} \rho^{6}+\cdots$.

In order to use the Dunham method, it is necessary to obtain the coefficients in a power series at $\xi=0\left(\xi=\left(R-R_{e}\right) / R_{e}\right)$ in a potential of the form

$V=h c a_{0} \xi^{2}\left(1+a_{1} \xi+a_{2} \xi^{2}+a_{3} \xi^{3}+\cdots\right)$

where $a_{0}=\omega_{e}^{2} / 4 B_{e}$ and $B_{e}=h / 8 \pi^{2} \mu R_{e}^{2} c$. Now comparing Eq. (6) to Eq. (5), one finds that $f_{2} / 2=h c a_{0} / R_{e}^{2}$. This means that

$f_{2}=4 \pi^{2} c^{2} \mu \omega_{e}^{2}$

If one continues the process until obtain the eight derivative term, then the values of $a_{1}, a_{2}, \ldots, a_{6}$ can be found related of the derivatives as

$$
\begin{aligned}
& a_{1}=\frac{R_{e} f_{3}}{12 \pi^{2} c^{2} \omega_{e}^{2} \mu} \\
& a_{2}=\frac{R_{e}^{2} f_{4}}{48 \pi^{2} c^{2} \omega_{e}^{2} \mu} \\
& a_{3}=\frac{R_{e}^{3} f_{5}}{240 \pi^{2} c^{2} \omega_{e}^{2} \mu} \\
& a_{4}=\frac{R_{e}^{4} f_{6}}{1440 \pi^{2} c^{2} \omega_{e}^{2} \mu} \\
& a_{5}=\frac{R_{e}^{5} f_{7}}{10080 \pi^{2} c^{2} \omega_{e}^{2} \mu} \\
& a_{6}=\frac{R_{e}^{6} f_{8}}{80640 \pi^{2} c^{2} \omega_{e}^{2} \mu}
\end{aligned}
$$


So, if the derivatives of an analytical form are known, the coefficient's values for Eq. (6) can be obtained. In Eq. (6) the rotation was neglected, but it can be added by rewriting the whole potential in a more convenient form [33] as

$T=\sum_{s k} Y_{s k}\left(v+\frac{1}{2}\right)^{s} j^{k}(j+1)^{k}$

Then, after some manipulation, it was shown [33] that the $Y_{s k}$ are related to spectroscopic constants in terms of coefficients $a_{n}$ as follows (here just two terms are presented):

$$
\begin{aligned}
-\alpha_{e} \sim Y_{11}= & \left(\frac{B_{e}^{2}}{\omega_{e}}\right)\left[6\left(1+a_{1}\right)+\left(\frac{B_{e}^{2}}{\omega_{e}^{2}}\right)\left(175+285 a_{1}-\frac{335 a_{2}}{2}\right.\right. \\
& +175 a_{5}+\frac{2295 a_{1}^{2}}{8}-459 a_{1} a_{2}+\frac{1425 a_{1} a_{3}}{4}-\frac{795 a_{1} a_{4}}{2} \\
& +\frac{1005 a_{2}^{2}}{8}-\frac{715 a_{2} a_{3}}{2}+\frac{1155 a_{1}^{3}}{4}-\frac{9639 a_{1}^{2} a_{2}}{16} \\
& \left.\left.+\frac{5145 a_{1}^{2} a_{3}}{8}+\frac{4677 a_{1} a_{2}^{2}}{8}-\frac{14259 a_{1}^{3} a_{2}}{16}+\frac{31185\left(a_{1}^{4}+a_{1}^{5}\right)}{128}\right)\right]
\end{aligned}
$$

$$
\begin{aligned}
\gamma_{e} & \sim Y_{21} \\
& =\left(\frac{6 B_{e}^{3}}{\omega_{e}}\right)\left(5+10 a_{1}-3 a_{2}+5 a_{3}-13 a_{1} a_{2}+15\left(\frac{a_{1}^{2}+a_{1}^{3}}{2}\right)\right)
\end{aligned}
$$

Although Dunham [33] derived the first 15 terms of $Y_{s k}$, only relations regarding the spectroscopic constants that can be compared to the ones obtained through DVR method $\left(\omega_{e}, \omega_{e} x_{e}, \omega_{e} y_{e}, \alpha_{e}, \gamma_{e}\right)$ were added in our code.

\section{Results and discussion}

The basis set generated in this work is prolapse free, so some comments about the prolapse are appropriate. The prolapse was first described by Faegri [34] when he found that some of his basis had total energy below the numerical values of reference. The prolapse occurs due to basis set deficiency at the innermost atomic region and it has been discussed [35] as a consequence of neglecting the minimax theorem. The drawbacks regarding prolapse are that it may lead to wrong results such as the incorrect binding energy of GdF [36], it may interfere in the self-consistent-field procedure [37] and it may be of matter for properties that are sensitive to the description of wave functions near the nucleus [38]. Because of these possible drawbacks, new prolapse-free basis sets [39,40] were developed and recently added into Dirac package.

The prolapse can be detected [41] by analyzing the behavior of the total energy and convergence when a tight function is added to the basis set. Since the energy increased close to $1 \times 10^{-7}$ hartree and there was no ill behavior in the SCF in the addition of a tight "s" function, the basis set can be considered as prolapse free.

The basis set's Gaussian exponents are shown in Table 1. The

\begin{tabular}{|c|c|c|c|c|c|}
\hline & $S$ & $\mathrm{P}$ & $\mathrm{D}$ & $\mathrm{F}$ & G \\
\hline 1 & $3.92320 \mathrm{E}+10$ & $6.48462 \mathrm{E}+07$ & $4.13493 \mathrm{E}+05$ & $6.12271 \mathrm{E}+03$ & $7.86628 \mathrm{E}-01$ \\
\hline 2 & $8.76678 \mathrm{E}+09$ & $2.31754 \mathrm{E}+07$ & $1.20277 \mathrm{E}+05$ & $2.25675 \mathrm{E}+03$ & $3.82893 \mathrm{E}-01$ \\
\hline 3 & $2.14111 \mathrm{E}+09$ & $8.69214 \mathrm{E}+06$ & $3.93064 \mathrm{E}+04$ & $9.31397 \mathrm{E}+02$ & $1.86374 \mathrm{E}-01$ \\
\hline 4 & $5.68903 \mathrm{E}+08$ & $3.41114 \mathrm{E}+06$ & $1.42763 \mathrm{E}+04$ & $4.23172 \mathrm{E}+02$ & $9.07180 \mathrm{E}-02$ \\
\hline 5 & $1.63697 \mathrm{E}+08$ & $1.39656 \mathrm{E}+06$ & $5.70098 \mathrm{E}+03$ & $2.08088 \mathrm{E}+02$ & $4.41572 \mathrm{E}-02$ \\
\hline 6 & $5.07753 \mathrm{E}+07$ & $5.94728 \mathrm{E}+05$ & $2.47611 \mathrm{E}+03$ & $1.08879 \mathrm{E}+02$ & \\
\hline 7 & $1.68995 \mathrm{E}+07$ & $2.62659 \mathrm{E}+05$ & $1.15714 \mathrm{E}+03$ & $5.95976 \mathrm{E}+01$ & \\
\hline 8 & $6.00770 \mathrm{E}+06$ & $1.19949 \mathrm{E}+05$ & $5.75583 \mathrm{E}+02$ & $3.35519 \mathrm{E}+01$ & \\
\hline 9 & $2.27070 \mathrm{E}+06$ & $5.64731 \mathrm{E}+04$ & $3.01467 \mathrm{E}+02$ & $1.90998 \mathrm{E}+01$ & \\
\hline 10 & $9.08298 \mathrm{E}+05$ & $2.73303 E+04$ & $1.64471 \mathrm{E}+02$ & $1.08089 \mathrm{E}+01$ & \\
\hline 11 & $3.82754 \mathrm{E}+05$ & $1.35556 \mathrm{E}+04$ & $9.24627 \mathrm{E}+01$ & $5.97852 \mathrm{E}+00$ & \\
\hline 12 & $1.69136 \mathrm{E}+05$ & $6.87034 \mathrm{E}+03$ & $5.29881 \mathrm{E}+01$ & $3.17750 \mathrm{E}+00$ & \\
\hline 13 & $7.80155 \mathrm{E}+04$ & $3.54761 \mathrm{E}+03$ & $3.06219 \mathrm{E}+01$ & $1.59542 \mathrm{E}+00$ & \\
\hline 14 & $3.73901 \mathrm{E}+04$ & $1.86084 \mathrm{E}+03$ & $1.76537 \mathrm{E}+01$ & $7.44012 \mathrm{E}-01$ & \\
\hline 15 & $1.85338 \mathrm{E}+04$ & $9.88569 \mathrm{E}+02$ & $1.00437 \mathrm{E}+01$ & & \\
\hline 16 & $9.45826 \mathrm{E}+03$ & $5.30332 \mathrm{E}+02$ & $5.57855 \mathrm{E}+00$ & & \\
\hline 17 & $4.94648 \mathrm{E}+03$ & $2.86447 \mathrm{E}+02$ & $2.99240 \mathrm{E}+00$ & & \\
\hline 18 & $2.63891 \mathrm{E}+03$ & $1.55314 \mathrm{E}+02$ & $1.53355 \mathrm{E}+00$ & & \\
\hline 19 & $1.42955 \mathrm{E}+03$ & $8.42867 \mathrm{E}+01$ & $7.42791 \mathrm{E}-01$ & & \\
\hline 20 & $7.82746 \mathrm{E}+02$ & $4.56464 \mathrm{E}+01$ & $3.36380 \mathrm{E}-01$ & & \\
\hline 21 & $4.31216 \mathrm{E}+02$ & $2.45960 \mathrm{E}+01$ & & & \\
\hline 22 & $2.37916 \mathrm{E}+02$ & $1.31477 \mathrm{E}+01$ & & & \\
\hline 23 & $1.30861 \mathrm{E}+02$ & $6.95145 \mathrm{E}+00$ & & & \\
\hline 24 & $7.14259 \mathrm{E}+01$ & $3.62456 \mathrm{E}+00$ & & & \\
\hline 25 & $3.85092 \mathrm{E}+01$ & $1.85824 \mathrm{E}+00$ & & & \\
\hline 26 & $2.04146 \mathrm{E}+01$ & $9.33968 \mathrm{E}-01$ & & & \\
\hline 27 & $1.05922 \mathrm{E}+01$ & $4.58837 \mathrm{E}-01$ & & & \\
\hline 28 & $5.35431 \mathrm{E}+00$ & $2.19682 \mathrm{E}-01$ & & & \\
\hline 29 & $2.62480 \mathrm{E}+00$ & $1.02201 \mathrm{E}-01$ & & & \\
\hline 30 & $1.24213 \mathrm{E}+00$ & $4.60635 \mathrm{E}-02$ & & & \\
\hline 31 & $5.64830 \mathrm{E}-01$ & $2.00544 \mathrm{E}-02$ & & & \\
\hline 32 & $2.45671 \mathrm{E}-01$ & & & & \\
\hline 33 & $1.01736 \mathrm{E}-01$ & & & & \\
\hline \multirow[t]{3}{*}{34} & $3.99290 \mathrm{E}-02$ & & & & \\
\hline & Total Energy (Numerical) & -58922.2960 & & & \\
\hline & Total Energy (Basis set): & -58922.2856 & & & \\
\hline
\end{tabular}
total energy difference between the numerical calculation and the energy obtained by DHF is close to 10 milli-Hartree, a very

Table 1

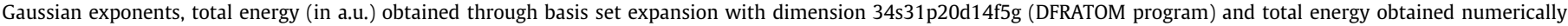
(GRASP program). 
good approximation if one considers the dimension of the basis set. The orbital properties for energy and mean values of $\langle r\rangle$ and $\langle 1 / r\rangle$ are shown in Table 2. The small deviations of properties when compared to the numerical values of reference confirm the good quality of the basis set.

It is necessary to describe 3 different regions of interaction that are important (small, medium and long range) in order to obtain a reliable analytical form of a diatomic potential. So, in general, the challenge is to obtain an analytical form that fits well all regions and a small root mean square (RMS) deviation suggests that the analytical form is describing well the diatomic potential.

The Rydberg parameters obtained in the fitting procedure are presented in Table 3. The parameters, along with Eq. (1), generates an accurate potential energy curve fitted from 4-Component CCSD $(\mathrm{T})+$ Gaunt level calculation for E121F's ground state. In the fitting procedure, the value of $R_{e}(4.10 \mathrm{bohr})$ and the dissociation energy $(181.41 \mathrm{kcal} / \mathrm{mol})$ were fixed. The obtained RMS deviation was $2.2369 \times 10^{-5}$ Hartree $(\approx 0.014 \mathrm{kcal} / \mathrm{mol})$ and this small value is an indication of the good quality of the analytical form. The potential energy curve for $\operatorname{CCSD}(\mathrm{T})$ without Gaunt interaction was also fitted and the RMS deviation was $2.60 \times 10^{-5}$ Hartree $(\approx 0.016 \mathrm{kcal} / \mathrm{mol})$, the dissociation energy was almost the same ( $181.3 \mathrm{kcal} / \mathrm{mol})$ and there was no difference with the $R_{e}$. The values of $d$ of the d-exponential (see Eq. (1)) obtained also in the fit process for the "CCSD(T)+Gaunt" and " $\operatorname{CCSD}(T)$ without Gaunt" potential energy curves were -0.06666460561 and -0.15668511513 , respectively.

In Table 4 the spectroscopic constants obtained from DVR and Dunham methods for the PEC at 4c-CCSD(T) level, for both PECs - with and without inclusion of Gaunt interaction. The inclusion of Gaunt interaction lowers the $\omega_{e}$ value by almost $5 \mathrm{~cm}^{-1}$. The
Table 3

The Rydberg parameters to generate the accurate potential energy curves for E121F ( $R_{e}=4.10$ bohr $)$.

\begin{tabular}{llll}
\hline Parameters & $\begin{array}{l}\text { With Gaunt } \\
\text { Interaction }\end{array}$ & $\begin{array}{l}\text { Without Gaunt } \\
\text { Interaction }\end{array}$ & Unit \\
\hline $\mathrm{a}_{1}$ & 1.20152526233 & 1.44336591631 & $\AA^{-1}$ \\
$\mathrm{a}_{2}$ & 0.35809852817 & 0.55684668340 & $\AA^{-2}$ \\
$\mathrm{a}_{3}$ & 0.13032032305 & 0.10212518026 & $\AA^{-3}$ \\
$\mathrm{a}_{4}$ & 0.02009939033 & 0.02290988112 & $\AA^{-4}$ \\
$\mathrm{a}_{5}$ & -0.00186940092 & -0.00022866390 & $\AA^{-5}$ \\
$\mathrm{a}_{6}$ & 0.00268927105 & 0.00006650991 & $\AA^{-6}$ \\
$\mathrm{a}_{7}$ & -0.00039283662 & -0.00000184688 & $\AA^{-7}$ \\
$\mathrm{a}_{8}$ & 0.00003625095 & 0.00000002358 & $\AA^{-8}$ \\
$\mathrm{a}_{9}$ & -0.00000130725 & -0.00000000015 & $\AA^{-9}$ \\
$\mathrm{a}_{10}$ & 0.00000002689 & 0.000000000 & $\AA^{-10}$ \\
$D_{\mathrm{e}}^{\mathrm{qRyd}}$ & 181.41 & 181.3 & $\mathrm{kcal} / \mathrm{mol}$ \\
RMS & 0.014 & 0.016 & $\mathrm{kcal} / \mathrm{mol}$ \\
$\mathrm{d}$ & -0.06666460561 & -0.15668511513 & \\
\hline
\end{tabular}

values of $\omega_{e} x_{e}$ and $\alpha_{e}$ remain practically the same. Nevertheless, the values of $\omega_{e} y_{e}$ and $\gamma_{e}$ have higher deviations. So in general the effects of Gaunt interaction are small. Probably the Gaunt interaction should be more pronounced in diatomic systems where both atoms are heavy as in the case of copernicium dimer [42], where $R_{e}$ increased $0.030 \AA$ and $D_{e}$ decreased from $0.123 \mathrm{eV}$ to $0.096 \mathrm{eV}$. In addition, the largest value for T1 diagnostic in all $\operatorname{CCSD}(\mathrm{T})$ molecular calculations was close to 0.017 , so there was no need to use any multireference electron correlation method.

The rovibrational spectra were obtained from the DVR procedure, and the lowest 16 states are presented in Table 5. It was observed that the inclusion of Gaunt interaction lowers the energy of all states. For example, the inclusion of Gaunt interaction for the

Table 2

Spinor eigenvalues, $\langle\mathrm{r}\rangle$ and $\langle 1 / \mathrm{r}\rangle$ results (in a.u.) obtained from numerical calculations (GRASP program) and basis set expansion (DFRATOM program) for element E121.

\begin{tabular}{|c|c|c|c|c|c|c|}
\hline & \multicolumn{3}{|l|}{ Numerical } & \multicolumn{3}{|c|}{ Basis set expansion } \\
\hline & e & $\langle 1 / \mathrm{r}\rangle$ & $\langle\mathbf{r}\rangle$ & $\mathrm{e}$ & $\langle 1 / \mathrm{r}\rangle$ & $\langle\mathrm{r}\rangle$ \\
\hline $1 \mathrm{~s}$ & -8807.575 & 232.071 & 0.008 & -8807.5732 & 232.071 & 0.008 \\
\hline $2 \mathrm{~s}$ & -1876.267 & 64.286 & 0.034 & -1876.2650 & 64.286 & 0.034 \\
\hline $2 \mathrm{p}-$ & -1843.525 & 67.123 & 0.026 & -1843.5233 & 67.123 & 0.026 \\
\hline $2 p$ & -1208.029 & 31.582 & 0.041 & -1208.0273 & 31.582 & 0.041 \\
\hline $3 s$ & -517.558 & 21.816 & 0.092 & -517.5562 & 21.816 & 0.092 \\
\hline $3 p-$ & -498.498 & 22.358 & 0.084 & -498.4956 & 22.358 & 0.084 \\
\hline $3 p$ & -341.859 & 13.030 & 0.111 & -341.8575 & 13.030 & 0.111 \\
\hline $3 d-$ & -308.843 & 12.898 & 0.094 & -308.8408 & 12.898 & 0.094 \\
\hline $3 d$ & -285.299 & 11.775 & 0.101 & -285.2972 & 11.775 & 0.101 \\
\hline $4 \mathrm{~s}$ & -157.203 & 9.095 & 0.198 & -157.2013 & 9.095 & 0.198 \\
\hline $4 p-$ & -147.062 & 9.160 & 0.192 & -147.0604 & 9.160 & 0.192 \\
\hline $4 p$ & -100.922 & 6.074 & 0.240 & -100.9197 & 6.074 & 0.240 \\
\hline $4 d-$ & -84.407 & 5.897 & 0.231 & -84.4055 & 5.897 & 0.231 \\
\hline $4 d$ & -77.683 & 5.491 & 0.243 & -77.6815 & 5.491 & 0.243 \\
\hline $4 \mathrm{f}-$ & -56.200 & 5.278 & 0.221 & -56.1977 & 5,278 & 0.221 \\
\hline $4 \mathrm{f}$ & -54.197 & 5.129 & 0.227 & -54.1951 & 5.129 & 0.227 \\
\hline $5 s$ & -46.031 & 4.172 & 0.389 & -46.0285 & 4.172 & 0.389 \\
\hline $5 p-$ & -41.107 & 4.112 & 0.391 & -41.1046 & 4.112 & 0.391 \\
\hline $5 p$ & -27.216 & 2.947 & 0.479 & -27.2140 & 2.947 & 0.479 \\
\hline $5 d-$ & -19.774 & 2.751 & 0.498 & -19.7716 & 2.751 & 0.498 \\
\hline $5 d$ & -17.913 & 2.586 & 0.522 & -17.9113 & 2.586 & 0.522 \\
\hline $5 f-$ & -8.756 & 2.268 & 0.569 & $-8,7545$ & 2.268 & 0.569 \\
\hline $5 f$ & -8.309 & 2.208 & 0.582 & -8.3066 & 2.208 & 0.582 \\
\hline $6 s$ & -11.368 & 1.948 & 0.757 & -11.3659 & 1.948 & 0.757 \\
\hline $6 p-$ & -9.282 & 1.861 & 0.788 & -9.2801 & 1.861 & 0.788 \\
\hline $6 p$ & -5.632 & 1.353 & 0.988 & -5.6301 & 1.353 & 0.988 \\
\hline $6 d-$ & -2.868 & 1.150 & 1.144 & -2.8664 & 1.150 & 1.144 \\
\hline $6 d$ & -2.508 & 1.077 & 1.208 & -2.5063 & 1.077 & 1.208 \\
\hline $7 \mathrm{~s}$ & -2.164 & 0.851 & 1.593 & -2.1619 & 0.851 & 1.593 \\
\hline $7 p-$ & -1.456 & 0.772 & 1.744 & -1.4541 & 0.772 & 1.744 \\
\hline $7 p$ & -0.740 & 0.544 & 2.349 & -0.7377 & 0.543 & 2.349 \\
\hline $8 s$ & -0.283 & 0.315 & 4.024 & -0.2809 & 0.315 & 4.018 \\
\hline $8 p-$ & -0.149 & 0.233 & 5.285 & -0.1491 & 0.233 & 5.282 \\
\hline $8 p$ & -0.098 & 0.168 & 7.299 & -0.0979 & 0.171 & 7.092 \\
\hline
\end{tabular}


Table 4

Spectroscopic constants for E121F given in $\mathrm{cm}^{-1}$, with and without Gaunt interaction at 4c-CCSD(T) level.

\begin{tabular}{|c|c|c|c|c|c|}
\hline & $\omega_{e}$ & $\omega_{e} x_{e}$ & $\omega_{e} y_{e}\left(\times 10^{-3}\right)$ & $\alpha_{e}\left(\times 10^{-3}\right)$ & $\gamma_{e}\left(\times 10^{-6}\right)$ \\
\hline \multicolumn{6}{|c|}{ Without Gaunt Interaction } \\
\hline DVR & 523.35 & 2.31 & 4.26 & 1.15 & 0.84 \\
\hline Dunham & 523.36 & 2.31 & 4.21 & 1.15 & 0.78 \\
\hline \multicolumn{6}{|c|}{ With Gaunt Interaction } \\
\hline DVR & 518.61 & 2.33 & 6.93 & 1.20 & 2.19 \\
\hline Dunham & 518.62 & 2.33 & 7.04 & 1.19 & 2.11 \\
\hline
\end{tabular}

Table 5

The lowest 16 vibrational energies and transitions (in $\mathrm{cm}^{-1}$ ) calculated at 4component $\operatorname{CCSD}(\mathrm{T})$, with and without Gaunt interaction level for $\mathrm{E} 121 \mathrm{~F}$.

\begin{tabular}{lll}
\hline Level & Without Gaunt Interaction & With Gaunt Interaction \\
\hline $\mathrm{v}=0$ & 261.14 & 258.78 \\
$\mathrm{v}=1$ & 779.88 & 772.75 \\
$\mathrm{~V}=2$ & 1294.04 & 1282.12 \\
$\mathrm{v}=3$ & 1803.63 & 1786.92 \\
$\mathrm{~V}=4$ & 2308.69 & 2287.19 \\
$\mathrm{~V}=5$ & 2809.23 & 2782.99 \\
$\mathrm{~V}=6$ & 3305.29 & 3274.35 \\
$\mathrm{~V}=7$ & 3796.90 & 3761.30 \\
$\mathrm{~V}=8$ & 4284.07 & 4243.90 \\
$\mathrm{~V}=9$ & 4766.84 & 4722.17 \\
$\mathrm{~V}=10$ & 5245.22 & 5196.15 \\
$\mathrm{~V}=11$ & 5719.27 & 5665.90 \\
$\mathrm{~V}=12$ & 6188.98 & 6131.44 \\
$\mathrm{~V}=13$ & 6654.21 & 6592.65 \\
$\mathrm{~V}=14$ & 7115.74 & 7050.17 \\
$\mathrm{~V}=15$ & 7573.32 & 7504.00 \\
Neighborhood Transitions & \\
$1 \rightarrow 0$ & 518.74 & 513.97 \\
$2 \rightarrow 1$ & 514.15 & 509.36 \\
$3 \rightarrow 2$ & 509.59 & 504.80 \\
$4 \rightarrow 3$ & 505.06 & 500.28 \\
$5 \rightarrow 4$ & 500.55 & 495.80 \\
$6 \rightarrow 5$ & 496.06 & 491.36 \\
$7 \rightarrow 6$ & 491.60 & 486.95 \\
$8 \rightarrow 7$ & 487.17 & 482.59 \\
$9 \rightarrow 8$ & 482.77 & 478.27 \\
$10 \rightarrow 9$ & 478.38 & 473.99 \\
$11 \rightarrow 10$ & 474.05 & 469.75 \\
$12 \rightarrow 11$ & 469.71 & 465.53 \\
$13 \rightarrow 12$ & 465.23 & 461.21 \\
$14 \rightarrow 13$ & 461.54 & 457.51 \\
$15 \rightarrow 14$ & 457.58 & 453.83 \\
\hline & & \\
& &
\end{tabular}

Table 6

Energies (in eV) and composition (net population of the main contributing AOs) of the highest bonding MOs of E121F obtained at 4-component B3LYP level with Gaunt interaction (Re distance of $4.10 \mathrm{bohr}$ ).

\begin{tabular}{|c|c|c|}
\hline Label & $\begin{array}{l}\text { Energy } \\
(\mathrm{eV})\end{array}$ & Composition \\
\hline \multicolumn{3}{|l|}{ E121F } \\
\hline HOMO & -4.64 & $\begin{array}{l}0.968|8 \mathrm{~s}(\mathrm{E} 121)+0.015| 6 \mathrm{dxx}(\mathrm{E} 121)+0.017 \mid 6 \mathrm{dzz} \\
(\mathrm{E} 121)+0.015 \mid 2 \mathrm{pz}(\mathrm{F})\end{array}$ \\
\hline HOMO-1 & -9.38 & $0.618|2 \mathrm{pz}(\mathrm{F})+0.111| 8 \mathrm{pz}(\mathrm{E} 121)$ \\
\hline HOMO-2 & -9.56 & $0.484|2 \mathrm{px}(\mathrm{F})+0.484| 2 \mathrm{py}(\mathrm{F})$ \\
\hline HOMO-3 & -9.79 & $0.391|2 \mathrm{px}(\mathrm{F})+0.391| 2 \mathrm{py}(\mathrm{F})+0.178 \mid 2 \mathrm{pz}(\mathrm{F})$ \\
\hline HOMO-4 & -15.15 & $0.491|7 \mathrm{py}(\mathrm{E} 121)+0.491| 7 \mathrm{px}(\mathrm{E} 121)$ \\
\hline HOMO-5 & -15.16 & $0.131|2 \mathrm{pz}(\mathrm{F})+0.547| 7 \mathrm{pz}(\mathrm{E} 121)$ \\
\hline \multicolumn{3}{|r|}{ 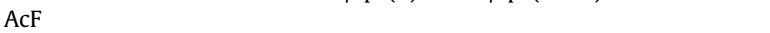 } \\
\hline HOMO & -4.21 & $0.914 \mid 7 \mathrm{~s}(\mathrm{Ac})$ \\
\hline HOMO-1 & -10.60 & $0.72 \mid 2 \mathrm{pz}(\mathrm{F})$ \\
\hline HOMO-2 & -10.66 & $0.476|2 \mathrm{px}(\mathrm{F})+0.476| 2 \mathrm{py}(\mathrm{F})$ \\
\hline HOMO-3 & -10.75 & $0.120|2 \mathrm{pz}(\mathrm{F})+0.412| 2 \mathrm{py}(\mathrm{F})+0.412 \mid 2 \mathrm{px}(\mathrm{F})$ \\
\hline HOMO-4 & -19.56 & $0.149|6 \mathrm{px}(\mathrm{Ac})+0.149| 6 \mathrm{py}(\mathrm{Ac})+0.609 \mid 6 \mathrm{pz}(\mathrm{Ac})$ \\
\hline HOMO-5 & -19.75 & $0.4969|6 \mathrm{py}(\mathrm{Ac})+0.497| 6 \mathrm{px}(\mathrm{Ac})$ \\
\hline
\end{tabular}

ground state decreases the energy value from $261.14 \mathrm{~cm}^{-1}$ to $258 \mathrm{~cm}^{-1}$, a decrease of $2.36 \mathrm{~cm}^{-1}$. Nevertheless, these small decreases can affect considerably the overall spectra since these small deviations are cumulative as one moves to higher states. The differences for $v=1, v=10$ and $v=15$ are $7.13 \mathrm{~cm}^{-1}$, $49.07 \mathrm{~cm}^{-1}$ and $69 \mathrm{~cm}^{-1}$, respectively. As a consequence, the Gaunt interaction, although small, is expected to influence the overall spectra considerably.

The composition and energies of the highest molecular orbitals obtained for E121F within the Mulliken framework are presented on Table 6. The highest occupied orbitals (from HOMO until HOMO-4) are mostly nonbonding. The covalent bonding is represented by HOMO- 5 orbital, which is practically degenerated with HOMO-4, and is composed by pz orbitals from F and E121F, the latter being the major contributor. The valence orbitals for AcF are
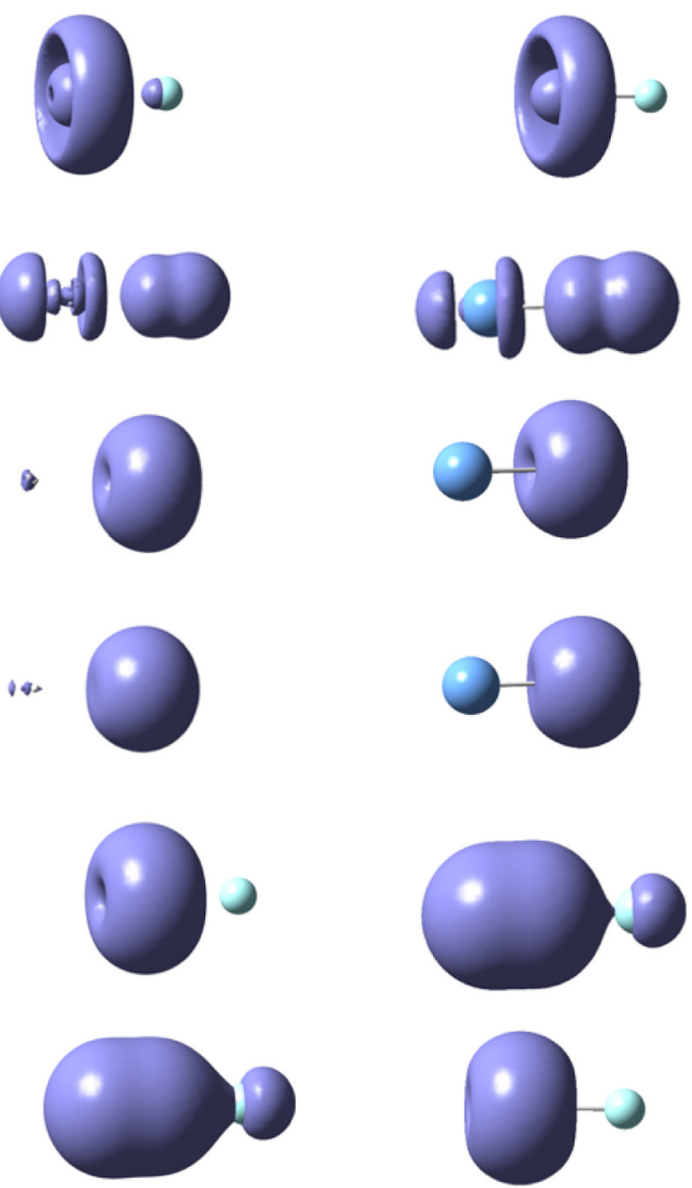

E121F

$\mathrm{AcF}$

Fig. 1. E121F́s highest bonding MOs obtained at 4c-B3lyp-Gaunt level for E121F (left column) and AcF, from HOMO (top) to HOMO-5 (bottom). They are fairly similar to each other. Isodensity value $=0.005$ a.u. 
also presented, and they have similarities with the ones from E121F - they are also mostly nonbonding.

The valence orbitals of E121F and AcF are compared in Fig. 1 and found to be very similar. On the other hand, the E121F's valence orbitals are compared also to data from literature for $\mathrm{NhF}$ [43] (Nh has configuration [Rn] $5 \mathrm{f}^{14} 6 \mathrm{~d}^{10} 7 \mathrm{~s}^{2} 7 \mathrm{p}^{1}$ ) and they differ significantly: the bonding orbital is the HOMO and has major contributions from fluorine's $2 \mathrm{pz}$ and Nihoniums $7 \mathrm{~s}$. The values of $D_{e}$ ( $\approx 3.5 \mathrm{eV}$ or $80.71 \mathrm{kcal} / \mathrm{mol}$ ) and $\mu_{e}$ (above 4 Debye) for NhF are also different when compared to the ones from E121F, while the values for AcF are much closer: the values of $D_{e}$ and $\mu_{e}$ for AcF are $7.26 \mathrm{eV}[44](\approx 167.42 \mathrm{kcal} / \mathrm{mol})$ and 2.42 Debye, and the respective values for $\mathrm{E} 121 \mathrm{~F}$ are $181.41 \mathrm{Kcal} / \mathrm{mol}(\approx 7.86 \mathrm{eV})$ and 3.15 Debye. So it seems that Ac and E121 should have similar chemical behavior despite the different atomic ground states of $[R n] 6 d^{1} 7 s^{2}$ and $[O g] 8 s^{2} 8 p^{1}$, and maybe the atomic ground state is less important than chemical bonding, as also observed [45] between Lu and Lr. In addition, no differences on bonding were observed when the Gaunt interaction was added at 4c-B3LYP level - the deviation for HOMO was below $0.01 \mathrm{eV}$ in agreement with atomic calculations on eka-actinium atom [12]

On the other hand, it is known that the straightforward extrapolation of properties in groups of the periodic table may result in erroneous predictions [4,1]. So some comments regarding the trends of $D_{e}, R_{e}$ and $\mu_{e}$ on monofluorides of group IIIB elements are convenient.

Based on the results obtained in this work, experimental data [46] and theoretical data for AcF [44] from literature, the following trend in $D_{e}$ of monofluorides of group IIB was established: ScF $(\sim 6.21 \mathrm{eV})<\mathrm{LaF}(\sim 6.83 \mathrm{eV}) \approx \mathrm{YF}(7.10 \mathrm{eV})<\mathrm{AcF}(7.26 \mathrm{eV})<\mathrm{E} 121 \mathrm{~F}$ $(7.86 \mathrm{eV})$. The $D_{e}$ experimental value for YF $(163.8 \pm 3.2 \mathrm{kcal} / \mathrm{mol})$ is slightly higher than the corresponding value for LaF $(157.5 \pm 4.1 \mathrm{kcal} / \mathrm{mol})$ but their experimental errors overlap. Regarding the equilibrium distances $R_{e}$ for ScF [47], YF [48], LaF
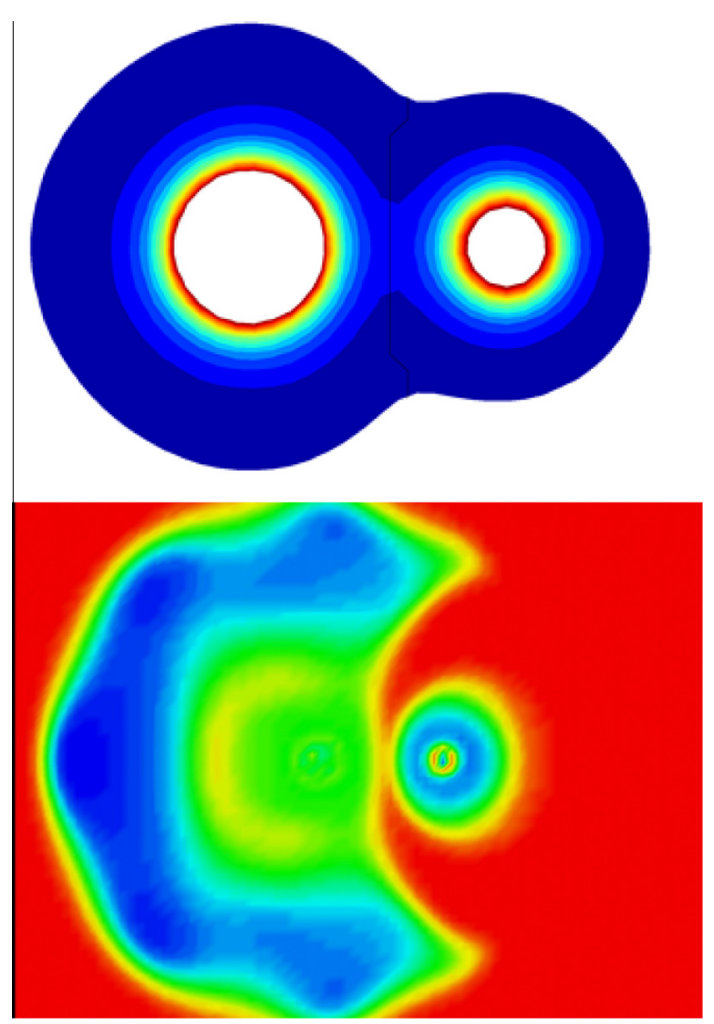

Fig. 2. Projections of electron density (on top, isodensity 0.005 a.u.) and ELF (isodensity 0.09 a.u.).
[28], AcF [28] the trend is ScF (3.377 bohr) < YF (3.643 bohr) $<$ LaF (3.829 bohr) < AcF (4.027 bohr) < E121F (4.10 bohr). Finally, if one compares the data from literature for ScF [47], LaF [49], YF [50] and results from this work then the trend observed for $\mu_{e}$ is ScF

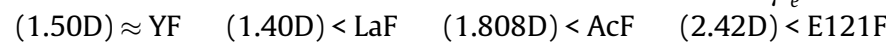
(3.15D), emphasizing that other values of $\mu_{e}$ for YF from literature [50] are higher than 1.40 Debye. So there is no evidence of a break of periodic trends in this group.

The projection of the electronic density and the Electron Localization function (ELF) are presented in Fig. 2. It can be observed from the projection of the electronic density that there is a small electron density between E121 and F. This bonding is indeed a mixture of ionic and covalent characters (polar covalent bond) with about 0.75 electron transfer from E121 to $\mathrm{F}$ in terms of Mulliken population analysis. From the Electron Localization function analysis, it can be seen that the electron density shows a more pronounced concentration at the E121 backside.

Due to their spatial distribution away from the bonding, the nonbonding electrons may be available for the addition of an extra atom or group. It was predicted [13] possible new molecules such as (E121) $\mathrm{X}_{3}$ ( $\mathrm{X}$ is a halogen) and its existence is plausible. Further theoretical investigation is under way in this direction.

\section{Conclusion}

A 4-component basis set suitable for molecular for E121 and numerical results for the E121 atom to assess the basis set is reliable are presented. The analytical form of q-Rydberg of order 10 proposed in this work succeeded in fitting the ground state PEC of $\mathrm{E} 121 \mathrm{~F}$ with the low root mean square deviation of $2.2369 \times 10^{-5}$ Hartree $(\approx 0.014 \mathrm{kcal} / \mathrm{mol})$. This value represents less than $0.008 \%$ of the value of the dissociation energy of E121F. The quality of the fit is highlighted by the close agreement of the spectroscopic constants given by both DVR and Dunham methods.

The Gaunt interaction effect on spectroscopic constants is small, but it is necessary to obtain reliable rovibrational data since deviations increase as $v$ also increases. The effect of Gaunt interaction on bonding is negligible.

The orbital analysis of the outermost frontier orbitals show a fair agreement with the corresponding ones from the AcF molecule and there was no evidence of a break of periodic properties. In addition, the bond of E121F is strong and it is polarized as expected for a bond between $\mathrm{F}$ and an element of group IIIB.

\section{Acknowledgments}

LGMM acknowledges CNPq (Conselho Nacional de Desenvolvimento Científico e Tecnológico, Brazilian Agency) for his postdoctoral scholarship (Grant number 157843/2015-7). DHTA Acknowledges CAPES (Coordenação de Aperfeiçoamento de Pessoal de Nível Superior) for his doctoral scholarship. The authors thank FINATEC (Fundação de Empreendimentos Científicos e Tecnológicos), FAPDF (Fundação de Apoio à Pesquisa do Distrito Federal) and FAPESP (2013/19289-0, 2016/07476-9) for financial support. The authors also acknowledge GridUnesp for computational support.

\section{References}

[1] M. Schädel, Philos. Trans. R. Soc. A 373 (2015) 20140191.

[2] Yu.Ts. Oganessian, V.K. Utyonkov, Yu.V. Lobanov, F.Sh. Abdullin, A.N. Polyakov, R.N. Sagaidak, I.V. Shirokovsky, Yu.S. Tsyganov, A.A. Voinov, G.G. Gulbekian, S.L. Bogomolov, B.N. Gikal, A.N. Mezentsev, S. Iliev, V.G. Subbotin, A.M. Sukhov, K. Subotic, V.I. Zagrebaev, G.K. Vostokin, M.G. Itkis, K.J. Moody, J.B. Patin, D.A Shaughnessy, M.A. Stoyer, N.J. Stoyer, P.A. Wilk, J.M. Kenneally, J.H. Landrum, J. F. Wild, R.W. Lougheed, Phys. Rev. C 74 (2006) 044602. 
[3] Yu.Ts. Oganessian, F.Sh. Abdullin, C. Alexander, J. Binder, R.A. Boll, S.N. Dmitriev, J. Ezold, K. Felker, J.M. Gostic, R.K. Grzywacz, J.H. Hamilton, R.A Henderson, M.G. Itkis, K. Miernik, D. Miller, K.J. Moody, A.N. Polyakov, A.V. Ramayya, J.B. Roberto, M.A. Ryabinin, K.P. Rykaczewski, R.N. Sagaidak, D.A Shaughnessy, I.V. Shirokovsky, M.V. Shumeiko, M.A. Stoyer, N.J. Stoyer, V.G. Subbotin, A.M. Sukhov, Yu.S. Tsyganov, V.K. Utyonkov, A.A. Voinov, G.K Vostokin, Phys. Rev. Lett. 109 (2012) 162501.

[4] A. Türler, V. Pershina, Chem. Rev. 113 (2013) 1237.

[5] P. Ludwig, T. Faestermann, G. Korschinek, G. Rugel, F. Dillmann, L. Fimiani, S. Bishop, P. Kumar, Phys. Rev. C 85 (2012) 024315.

[6] G.L. Malli, J. Chem. Phys. 124 (2006) 071102.

[7] V. Pershina, A. Borschevsky, J. Anton, J. Chem. Phys. 136 (2012) 134317.

[8] C. Thierfelder, P. Schwerdtfeger, A. Koers, A. Borschevsky, B. Fricke, Phys. Rev. A 80 (2009) 022501

[9] P.S. Miranda, A.P.S. Mendes, J.S. Gomes, C.N. Alves, A.R. de Souza, J.R. Sambrano, R. Gargano, L.G.M. de Macedo, J. Braz. Chem. Soc. 23 (2012) 1104.

[10] P. Pyykko, Chem. Rev. 112 (2012) 371.

[11] P. Schwerdtfeger, L.F. Pasteka, A. Punnett, P.O. Bowman, Nucl. Phys. A 944 (2015) 551.

[12] E. Eliav, A. Landau, Y. Yshikawa, U. Kaldor, J. Phys. B 35 (2002) 1963.

[13] P. Pyykko, Phys. Chem. Chem. Phys. 13 (2011) 161

[14] V.I. Nefedov, M.B. Trzhaskovkaya, V.G. Yarzhemskii, Doklady Phys. Chem. 408 (2006) 149.

[15] O. Matsuoka, Y. Watanabe, Comput. Phys. Commun. 139 (2001) 218.

[16] L.G.M. de Macedo, A.C. Borin, A.B.F. da Silva, At. Data Nucl. Data Tables 93 (2007) 931

[17] R.L.A. Haiduke, L.G.M. de Macedo, R.C. Barbosa, A.B.F. da Silva, J. Comput. Chem. 25 (2004) 1904.

[18] P.R. Chowdhury, C. Samanta, D.N. Basu, At. Data Nucl. Data Tables 94 (2008) 781.

[19] K.G. Dyall, I.P. Grant, C.T. Johnson, F.A. Parpia, E.P. Plummer, Comput. Phys Commun. 55 (1989) 425.

[20] L. Visscher, K.G. Dyall, At. Data Nucl. Data Tables 67 (1997) 207.

[21] R. Bast, H.J.Aa. Jensen, T. Saue, L. Visscher, Dirac, a relativistic ab initio electronic structure program, Release Dirac12, 2012.
[22] L. Visscher, K.G. Dyall, T.J. Lee, Int. J. Quantum Chem.: Quantum Chem. Symp. 29 (1995) 411.

[23] L. Visscher, E. Eliav, U. Kaldor, J. Chem. Phys. 115 (2001) 9720.

[24] T. Saue, T. Helgaker, J. Comput. Chem. 23 (2002) 814

[25] L. Visscher, Theor. Chem. Acc. 98 (1997) 68.

[26] G.L. Malli, A.B.F. da Silva, Y. Ishikawa, Phys. Rev. A 47 (1993) 143.

[27] K.G. Dyall, Theor. Chem. Acc. 117 (2007) 491

[28] J.K. Laerdahl, K. Faegri Jr., L. Visscher, T. Saue, J. Chem. Phys. 109 (1998) 10806.

[29] C.S. Esteves, H.C.B. de Oliveira, L. Ribeiro, R. Gargano, K.C. Mundim, Chem. Phys. Lett. 427 (2006) 10.

[30] K.C. Mundim, C. Tsallis, Int. J. Quantum Chem. 58 (1996) 373.

[31] J.J.S. Neto, L.S. Costa, Braz. J. Phys. 28 (1998) 1.

[32] H.V.R. Vila, L.A. Leal, L.A. Ribeiro, J.B.L. Martins, G.M.e. Silva, R. Gargano, J. Mol. Spect. 273 (2012) 26

[33] J.L. Dunham, Phys. Rev. 41 (1932) 721.

[34] K. Faegri Jr., Theor. Chem Acc. 105 (2001) 252.

[35] H. Tatewaki, Y. Watanabe, J. Chem. Phys. 121 (2004) 4528.

[36] H. Tatewaki, Y. Watanabe, J. Comput. Chem. 24 (2003) 1823.

[37] H. Tatewaki, Y. Michizuki, Theor. Chem. Acc. 109 (2003) 40.

[38] H.M. Quiney, J.K. Laerdahl, T. Saue, K. Faegri Jr., Phys. Rev. A 57 (1998) 920

[39] T.Q. Teodoro, A.B.F. da Silva, R.L.A. Haiduke, J. Chem. Theory Comput. 10 (2014) 3800

[40] T.Q. Teodoro, A.B.F. da Silva, R.L.A. Haiduke, J. Chem. Theory Comput. 10 (2014) 4761.

[41] H. Tatewaki, T. Koga, Y. Mochizuki, Chem. Phys. Lett. 375 (2003) 399.

[42] T. Hangele, M. Dolg, Chem. Phys. Lett. 616-617 (2014) 222.

[43] M. Seth, P. Schwerdtfeger, K. Faegri, J. Chem. Phys. 111 (1999) 6422.

[44] M. Sekiya, T. Noro, T. Koga, S.L. Saito, J. Comput. Chem. 31 (2010) 497.

[45] W.-H. Xu, P. Pyykko, Phys. Chem. Chem. Phys. 18 (2016) 17351.

[46] D.L. Hildebrand, K.H. Lau, J. Chem. Phys. 102 (1995) 3769.

[47] A. Chrissanthopoulos, G. Maroulis, J. Phys. B: At. Mol. Opt. Phys. 34 (2001) 121.

[48] S. Abdul-Al, M. Korek, A. Allouche, M.A. Frécon, Chem. Phys. 315 (2005) 183.

[49] B. Simard, A.M. James, J. Chem. Phys. 97 (1992) 4669.

[50] M. Korek, S.N. Abdul-Al, Chem. Phys. 355 (2009) 130. 